\title{
Are enhanced skills programs undermining family medicine?
}

\author{
— Cite as: CMAJ 2019 January 14;191:E57-8. doi: 10.1503/cmaj.109-5697
}

Posted on cmajnews.com on Dec. 12, 2018.

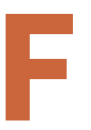
amily medicine is facing an existential crisis. The specialty is struggling to attract medical graduates to its ranks and increasing numbers of family doctors are narrowing their practices based on niche interests. Some blame the rise of enhanced skills programs and certificates of added competency for creating these niches. But proponents say enhanced skills training isn't at odds with "cradle to grave" care.

According to Dr. Jock Murray, former director of the family medicine enhanced skills program at Dalhousie University, "the solution is really to make broad scope family medicine more appealing."
Only a third of medical graduates specialize in family medicine and about $15 \%$ of Canadians don't have family doctors, Murray said at the Family Medicine Forum in Toronto. That's held steady even as the number of residency positions in family medicine has increased, making the specialty one of the least competitive in the 2018 residency match.

One in five family medicine residents takes an extra year to complete an enhanced skills program in a specialty of interest. In theory, this additional training should expand the scope of services they provide. But, in practice, some programs have become a back door to more com-

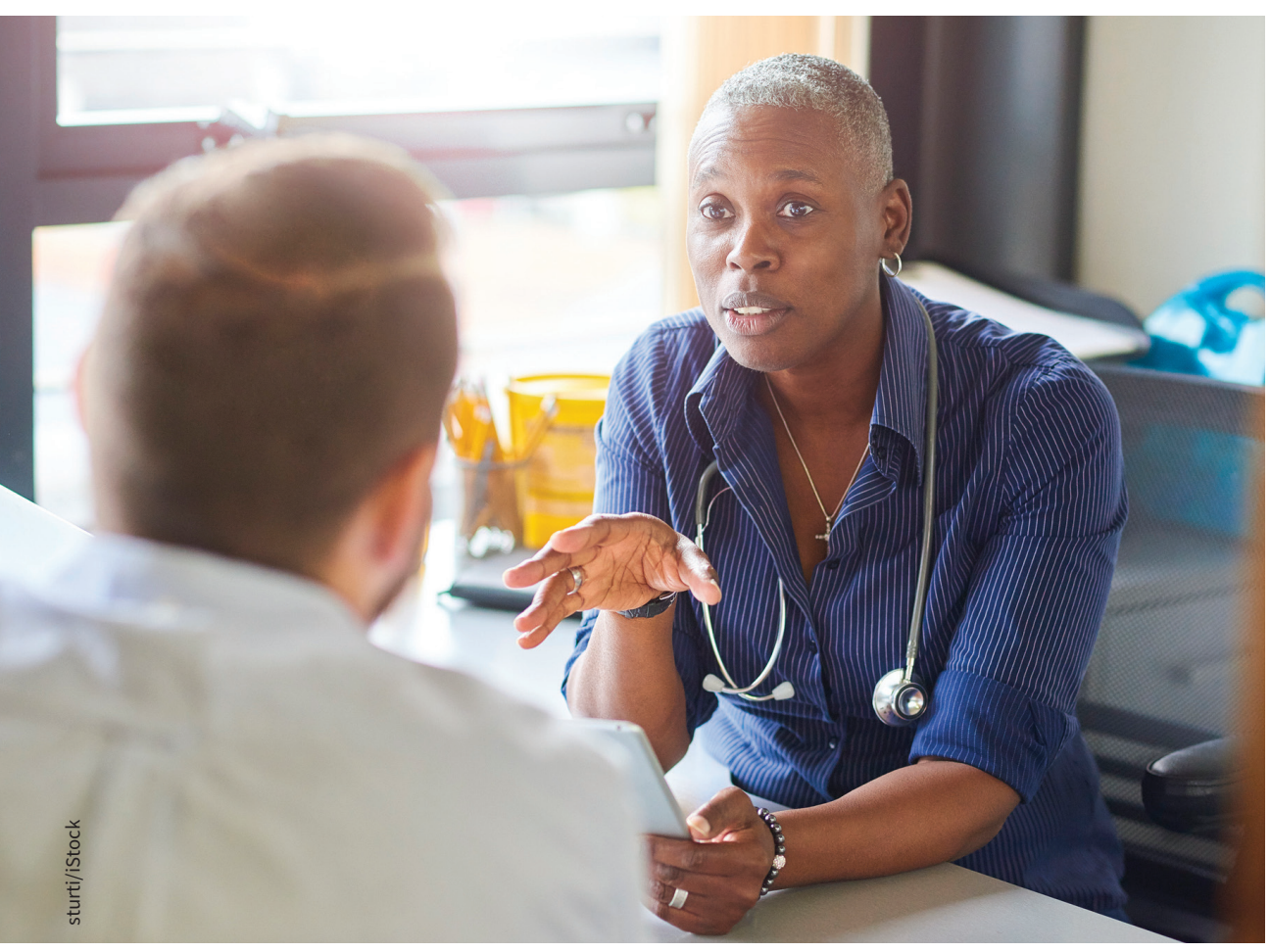

Fewer family doctors want to provide comprehensive "cradle to grave" care, according to speakers at a recent family medicine conference. petitive specialties. "One of the criticisms of enhanced skills programs is we used that carrot quite a bit," said Murray.

The problem is most apparent in emergency medicine, the oldest and most popular of Canada's 30 enhanced skills programs. Most family medicine residents who complete the program end up working almost exclusively in emergency medicine. Less than $10 \%$ maintain a mixed practice in which they also provide primary care.

There are also concerns that worsening physician shortages across medicine in the next decade will lead to "poaching" of family doctors with enhanced skills to fill in for other specialists, further eroding access to comprehensive care. Emergency medicine will face a shortage of 1500 physicians by 2026, Murray said, "so there are lots of jobs" for family doctors with emergency medicine certificates.

Meanwhile, family doctors without enhanced skills are losing their footholds in domains where they've always practised, from emergency medicine to obstetrics to palliative care. "Ontario has started this trend, and British Columbia is following, where colleges of physicians and surgeons are looking at requiring extra training or courses," Murray explained.

According Dr. Daniel Grushka, director of the enhanced skills program at Western University, these problems can be fixed only by addressing the reasons family doctors are narrowing their practices. He shared the results of a recent poll that found more than a third of graduating family medicine residents had no intention of providing comprehensive care.

"You need a lot of clinical confidence in family medicine," Grushka explained, 
and the increasing complexity of broad scope practice can be daunting. "One of the things l've heard over the last 10 years from family medicine residents is they just don't feel ready." The overhead involved in family practice also makes it difficult to work part-time or take time off.

Medical schools and residency programs need to provide better mentorship and exposure to family medicine throughout training, Grushka said. "There's no reason why they need to see nephrolo- gists from day one. They need to see how a family doctor works."

That includes pushing back against the perception that enhanced skills are necessary to practise in certain domains, said Murray. "Family physicians are well trained and ready to work anywhere in the country and enhanced skills programs are not intended to change that, but we need to get that message to colleges of physicians and surgeons and to hospital credentialing boards."
Integrating enhanced skills training throughout residency may also encourage trainees to continue into mixed practice, Murray said. Some medical leaders have proposed extending family medicine residency to include some enhanced skills training, he added. However, "the funders are not interested in talking about this right now, so I don't know if anything is going to change."

Lauren Vogel, CMAJ 